\title{
A generalized analytical solution of groundwater head response to dual tide in a multilayered island leaky aquifer system
}

\author{
Zhi-Xue Z'hao ${ }^{1}$, Yonghong $\mathrm{Hao}^{1}$, Tongke Wang ${ }^{1}$, T J Yeh², and Ming Zhang ${ }^{3}$ \\ ${ }^{1}$ Tianjin Normal University \\ ${ }^{2}$ The University of Arizona \\ ${ }^{3}$ National Institute of Advanced Industrial Science and Technology Tsukuba Center \\ Tsukuba Central
}

September 25, 2021

\begin{abstract}
The hydraulic properties of coastal aquifer systems are relevant to various hydrogeological, hydro-ecological and engineering problems. This study presents an analytical solution for predicting groundwater head fluctuations induced by dual-tide in multilayered island aquifer systems, consisting of an unconfined aquifer on the top and any number of leaky aquifers below. The solution was derived via the methods of matrix differential calculus and separation of variables. It is more general than any existing analytical solutions for the tidal pressure propagation since the new solution can consider multilayered aquifer systems along with the effects of leakage and aquifer length. Using this solution, we illustrated potential errors that may occur due to neglecting one or more vital factors affecting groundwater fluctuations. Besides, we articulated the groundwater response to the dual-tide in complex coastal aquifers. Considering that some thin semipermeable layers may be ignored in practical field investigation, we also demonstrated the effects due to simplification of aquifer layers. The results showed that with the increase in the number of overlapped leaky layers, the tidal propagation in the bottom part of multilayered aquifer system approaches that in a single confined aquifer with the same transmissivity and storage.
\end{abstract}

\section{Hosted file}

A Generalized Analytical Solution of Groundwater Head Response to Dual Tide in a Multilayered Island Le available at https://authorea.com/users/436832/articles/538883-a-generalized-analyticalsolution-of-groundwater-head-response-to-dual-tide-in-a-multilayered-island-leakyaquifer-system 


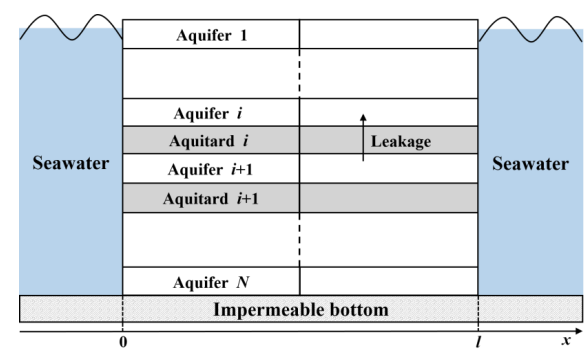

FIGURE 1 Schematic representation of a multilayered leaky island aquifer system 


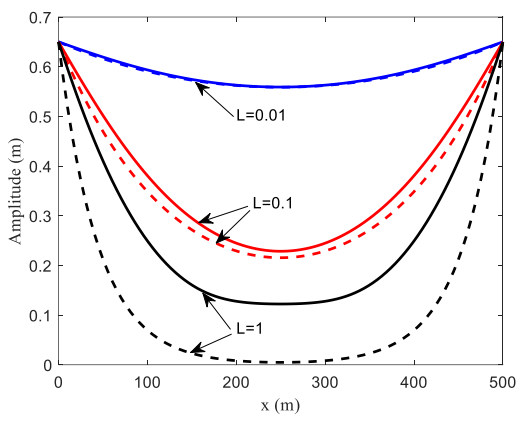

FIGURE 2 Amplitude attenuation of tidal fluctuations across the island width under different leakages $(L)$. Solid lines denote the present solution, dashed lines for Sun et al. $(2008)(s=100, T=1)$. 


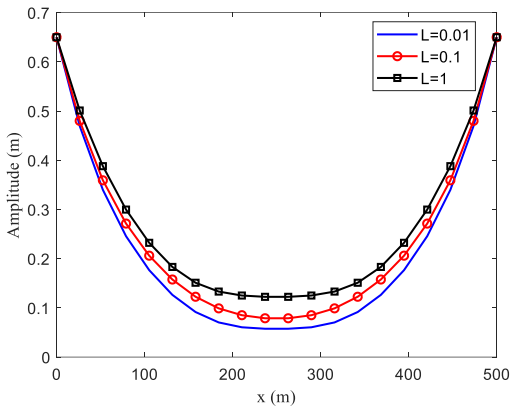

FIGURE 3. Changes in the amplitude of water table fluctuation across the island width in the unconfined aquifer with different leakages, $L(s=100, T=1)$. 


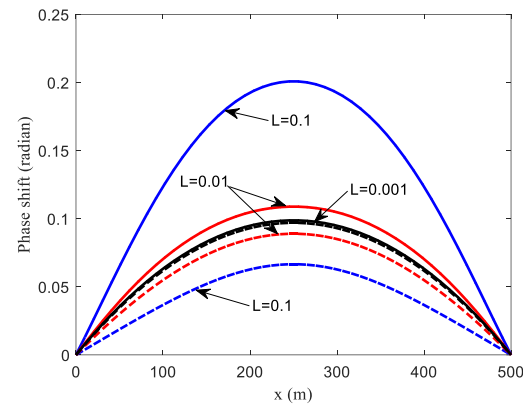

FIGURE 4. Change of groundwater phase shifts in the confined aquifer under

different leakages, $L$. Solid lines denote the present solution, and dashed lines for Sun et al. (2008) $(s=100, T=1)$. 


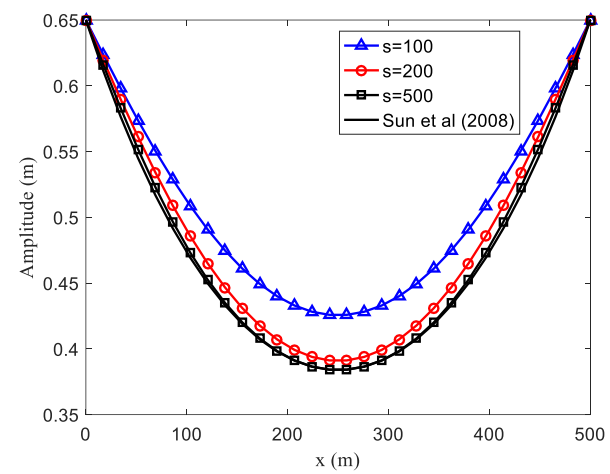

FIGURE 5 Effects of phreatic aquifer's storativity on the amplitude of hydraulic head

fluctuations across the island width. $s$ is the ratio of storativities between the top

phreatic aquifer and lower confined aquifer ( $L=0.1 /$ day, $T=1$ ). 


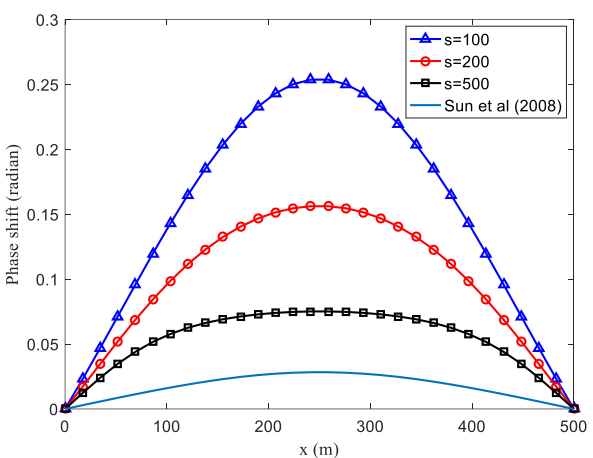

FIRURE 6 Effects of phreatic aquifer's storativity on the phase shift of hydraulic

head fluctuations across the island width. $s$ is the ratio of storativities between the top

phreatic aquifer and lower confined aquifer ( $L=0.1 /$ day, $T=1$ ). 


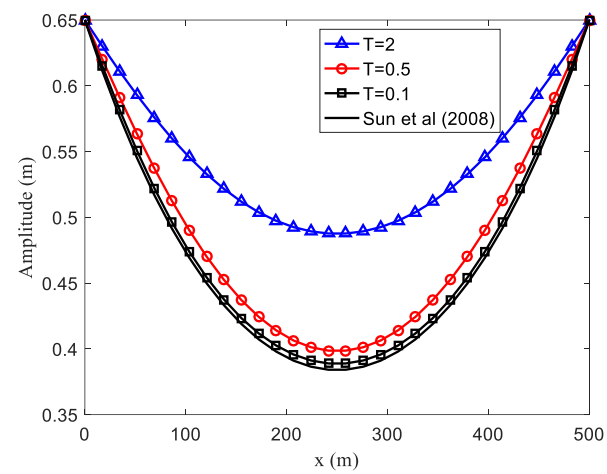

FIGURE 7 The effects of transmissivity ratio, $T$, between the top phreatic aquifer and

lower confined aquifer on amplitude of hydraulic head fluctuations in the confined aquifer $(L=0.1 /$ day, $s=100)$. 


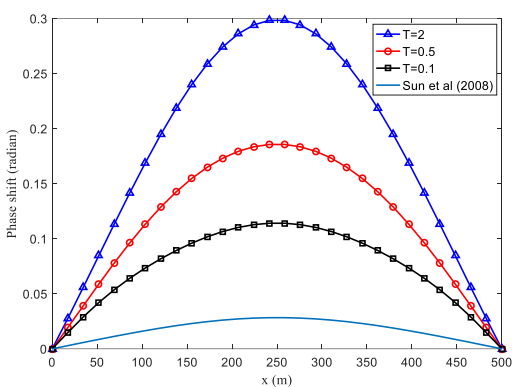

FIGURE 8 The effects of transmissivity ratio, $T$, between the top phreatic aquifer and

lower confined aquifer on phase shift of hydraulic head fluctuations in the confined aquifer ( $L=0.1 /$ day, $s=100$ ). 


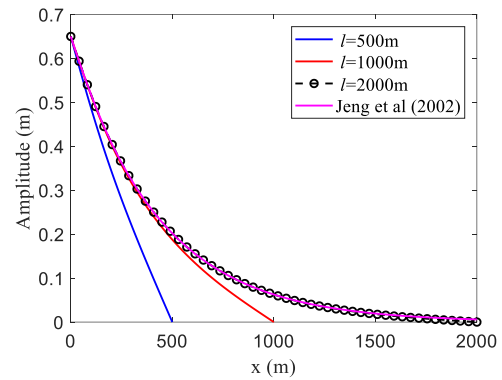

FIGURE 9 Attenuation of hydraulic head amplitude in the confined aquifer with different lengths, $l$. ( $L=1 /$ day, $s=100, T=1)$. 

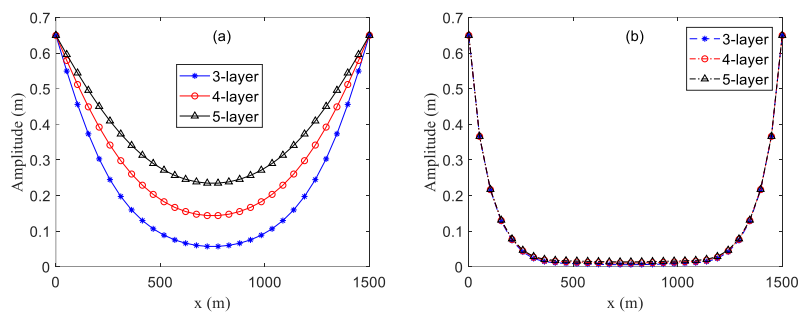

FIGURE 10 Attenuation of amplitudes of groundwater heads in bottom-layer (a) and top-layer aquifer (b) in multiple aquifer systems. 

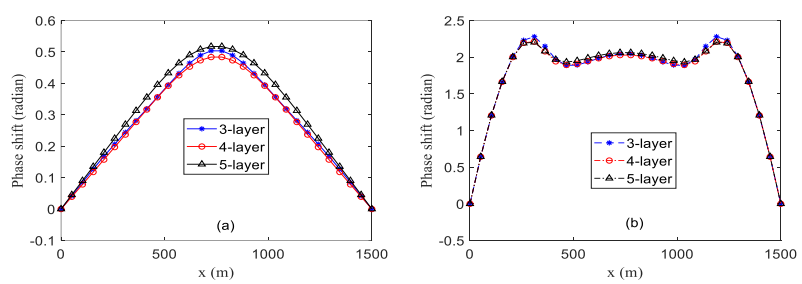

FIGURE 11 Phase shifts of groundwater heads in bottom-layer (a) and top-layer

aquifer (b) in multiple aquifer systems. 


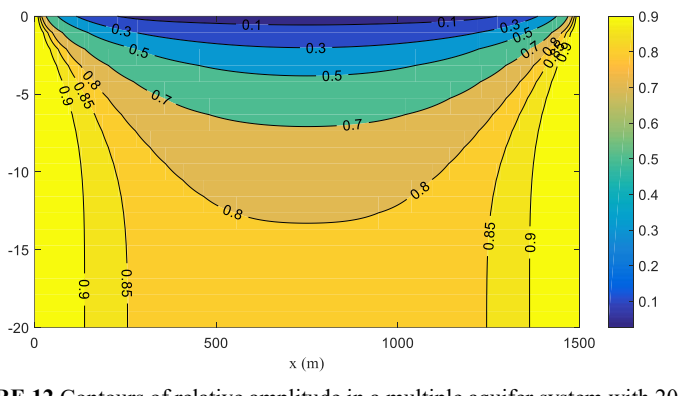

FIGURE 12 Contours of relative amplitude in a multiple aquifer system with 20 


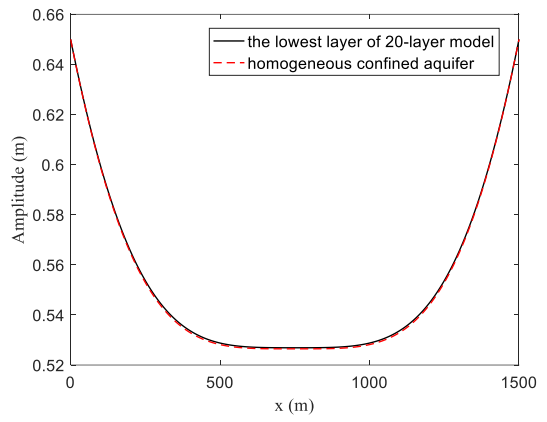

FIGURE 13 The amplitude in the lowest layer of the 20-layer model versus that in a

homogeneous confined aquifer with the same transmissivity and storage. 


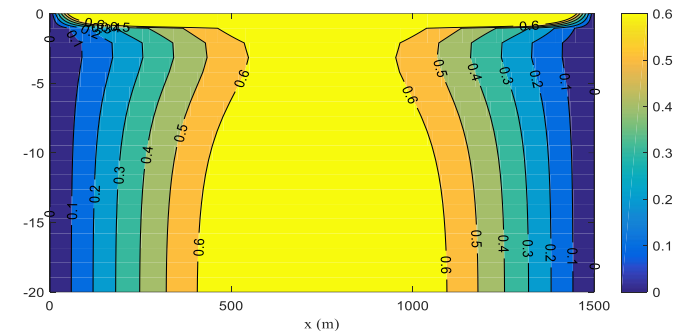

FIGURE 14 Contours of phase shift in a multiple aquifer system with 20 layers. 


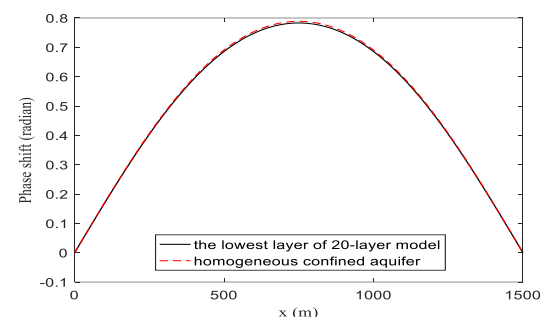

FIGURE 15 The phase shift in the lowest layer of the 20-layer model versus that in a

homogeneous confined aquifer with the same transmissivity and storage.

\section{Hosted file}

Table 1.docx available at https://authorea.com/users/436832/articles/538883-a-generalizedanalytical-solution-of-groundwater-head-response-to-dual-tide-in-a-multilayered-islandleaky-aquifer-system 